\title{
Welding of Very Dissimilar Materials (Fe-Al)
}

\author{
JUDY SCHNEIDER ${ }^{1,3}$ and RON RADZILOWSKI ${ }^{2}$ \\ 1.-Mechanical Engineering Department, Mississippi State University, Mississippi State, MS, \\ USA. 2.-Metallurgical Technology Corporate, Severstal North America, Dearborn, MI, USA. \\ 3.—e-mail: schneider@me.msstate.edu
}

\begin{abstract}
Designers of transportation vehicles (air, land, or sea) continually seek ways to reduce vehicle weight in response to increasing fuel economy mandates, mission requirements, or other competitive pressures. One way to do this is by the selection of material types and their properties based on functional and structural requirements. While these material changes can help meet performance mandates, their implementation in a production environment relies on retaining economic competitiveness. This article traces the history of the various joining processes relevant to the current challenge in joining the very dissimilar families of steel (Fe) and aluminum (Al) alloys.
\end{abstract}

\section{INTRODUCTION}

The production of large engineered structures has always relied on the ability to join smaller components or subassemblies. The selected joining technology must not reduce the strength of the parent material and cannot result in environmental degradation. Joining of materials can be accomplished using mechanical fasteners such as bolts, screws, rivets, clinching, clamping, and folding; however, they can be time consuming to install and may add extra weight. When considering cost reduction in assembly applications, the use of other fabrication methods amenable to automation are of interest. Thus the use of "welding" to consolidate or coalesce two parts has provided an attractive alternative to mechanical fasteners in an automated production environment such as the automotive industry.

\section{BACKGROUND}

The various welding techniques currently in use have a long history. Manual hammer welding was used first to consolidate the noble metals such as gold and later iron. ${ }^{1}$ Welding or joining of these materials in the solid state relied on the pressure transmitted, which broke up surface oxides and allowed the metal surfaces to bond atomically. Later pressure welding was automated by forges, often at elevated temperatures. ${ }^{2}$

In the $1880 \mathrm{~s}$, the introduction of the acetylene torch made fusion welding possible by local melting of two materials. ${ }^{1,3}$ Depending on the alloy system, a weld rod or wire could be used to alloy the welded region to improve material properties. Surface oxides were either mechanically removed or dissociated by the heat with or without the use of chemical fluxes. Various weld configurations were developed for continuous seams as well as discontinuous spots. The ability to automate these welding processes made them attractive to assembly factories and especially to the automotive industry.

With the introduction of fusion welding, the selection of a particular joining process for an application became driven by the resulting metallurgical microstructure that forms. Although the use of mechanical fasteners can avoid these changes to the microstructure, an additional component is introduced at a weight penalty. Cracks between the two joined parts can serve as a potential corrosion site, although incorporation of a sealant can help prevent crevice corrosion. In contrast, fusion welding considers thermal management to avoid the formation of brittle intermetallic phases. Because of the disruption in the parent material microstructure, galvanic corrosion can become an issue depending on the alloy combination.

\section{Development of Welding within Similar Material Families}

Welding, or material coalescence, relies on the application of pressure and/or temperature over time first to break down existing surface oxides thereby allowing atomic bonding to occur between the surfaces. Careful control of time at pressure or 
temperature, along with local alloying, can promote the formation of favorable phases between the two materials to strengthen the weld interface.

Fusion welding sources locally melt the material being joined thereby liberating surface oxides either through temperature or the use of chemical fluxes. The resulting metallurgy in the fusion weld zone is a solidification structure. Moving away from the solidification structure to the unaffected parent material, the material properties undergo variations corresponding to the range of temperatures. The fusion welding sources developed have a range of heat fluxes, which can be selected to manage the temperature. ${ }^{3}$ In the case of heavily alloyed materials, changes to the complex microstructure can occur with detrimental results on the mechanical properties. Liquidation and/or solidification cracking are common defects that can occur in heavily alloyed similar material. ${ }^{3}$ The development of fusion weldable alloys thus relies on collaboration between the material developer and the welder. Lower heat flux sources or the use of hybrid processes are developed as is the material alloy system to increase the thermal stability of the various complex phases in the alloys.

In contrast to fusion welding, solid-state joining processes rely on some type of pressure to break the oxide layer and promote atomic bonding. Deformational or adiabatic heat is generated, which can be augmented by additional thermal energy. In hammer welding, the blows of a hammer provided the pressure to coalescence two pieces of metal. ${ }^{2}$ Pressure can also be applied via explosive bonding ${ }^{4,5}$ or magnetic fields ${ }^{6,7}$ that shorten the time at temperature to minimize changes to the microstructure.

Because of the lower temperatures that avoid melting of materials, solid-state joining processes continue to be developed. These processes are in response to new highly alloyed advanced alloys, which are deemed "impossible" or difficult to fusion weld including dissimilar materials from the same family. By solid-state coalescence, the materials are welded without liquidus formation, thus overcoming issues with solidification cracking and liquation. Various methods can be employed to generate motion between workpieces to generate heat and deformation for bonding such as ultrasonic or friction. Ultrasonic welding (USW) uses a vibratory action to cause small micron-scale displacements between metal surfaces at frequencies on the order of $15 \mathrm{kHz} .^{8}$ The electronics industry uses USW on small-scale parts such as thin sheets and wires. Friction welding relies on friction generated between two rotationally symmetric components to soften the surfaces that are the pressed together expelling surface oxides. A later adaptation is friction-stir welding which uses a non-consumable tool to provide frictional and deformational heating to stir the workpieces together. ${ }^{9}$ The high strains encountered in the process break up the surface oxides, allowing atomic bonding to occur between the surfaces. ${ }^{9}$

\section{Development of Welding for Very Dissimilar Material Families}

As methods to join new alloys and dissimilar combinations develop, the next push is the joining of very dissimilar materials. While initially this has meant dissimilar alloys within the same family, it has more recently addressed materials in different families or classifications such as Fe and its alloys to $\mathrm{Al}$ and its alloys. Because of the limited solubility in the $\mathrm{Fe}-\mathrm{Al}$ binary system, shown in Fig. 1, various intermetallics are expected to form. ${ }^{10,11}$ In addition, the disparity between melting temperatures and thermal properties makes the combination difficult to coalescence. ${ }^{12,13}$ Various processes evaluated for $\mathrm{Fe}-\mathrm{Al}$ joints are summarized in Table I.

In welding of $\mathrm{Fe}$ or steel to $\mathrm{Al}$ and its alloys, the formation of an intermetallic compound (IMC) layer needs to be controlled. Initial attempts using resistance spot welding (RSW) of 5xxx series $\mathrm{Al}$ alloy to lowcarbon steel used a transition material to suppress the Fe-Al reaction layer. ${ }^{14,15}$ To avoid the costs of the transition metal, more recent studies on this material combination used a cover plate over the $\mathrm{Al}$ sheet to transmit the heat as illustrated in Fig $2 .{ }^{16,17}$ To minimize the temperature, high-energy sources have been pursued such as electron and laser beams due to the flexibility in accommodating various joint designs.

In studies using either electron beam welding (EBW) or laser beam welding (LBW), an inverse correlation was noted between the thickness of the reaction layer or IMC and the lap joint properties. ${ }^{18,19}$ Control of the heat input was used to create a liquid/solid-state weld, which limited the thickness of the IMC. ${ }^{20,21}$ A variation in the IMC thickness was obtained by either direct heating of the aluminum, ${ }^{22}$ indirect heating of the aluminum by the steel, ${ }^{21}$ defocused laser beam (LB) to directly heat the steel ${ }^{19,20}$ or heating of a filler wire to promote a braze joint. ${ }^{23,24}$

Although success has been achieved experimentally with fusion welding of $\mathrm{Fe}-\mathrm{Al}$, solid-state processes continue to be an area of interest to consolidate the very dissimilar materials. Use of pressure can be promoted by various methods of providing an impact. In explosive welding (EXW), no heat is involved; rather, pressure is provided from a shock wave to break the oxides and promote atomic-level bonding at the interface. ${ }^{4}$ Associated strain rates with EXW have been estimated at $10^{7} \mathrm{~s}^{-1}$. The process has shown promise for very dissimilar materials including $\mathrm{Fe}$ to $\mathrm{Al}$ in simple shapes such as flat plates or cones. ${ }^{4}$ Similar atomiclevel bonds can be obtained without temperature increases by use of a magnetic pulse to provide the pressure usually in tubular structures. ${ }^{6,7}$ This confines the IMC to a very thin layer without metallurgical changes to the adjacent material. 


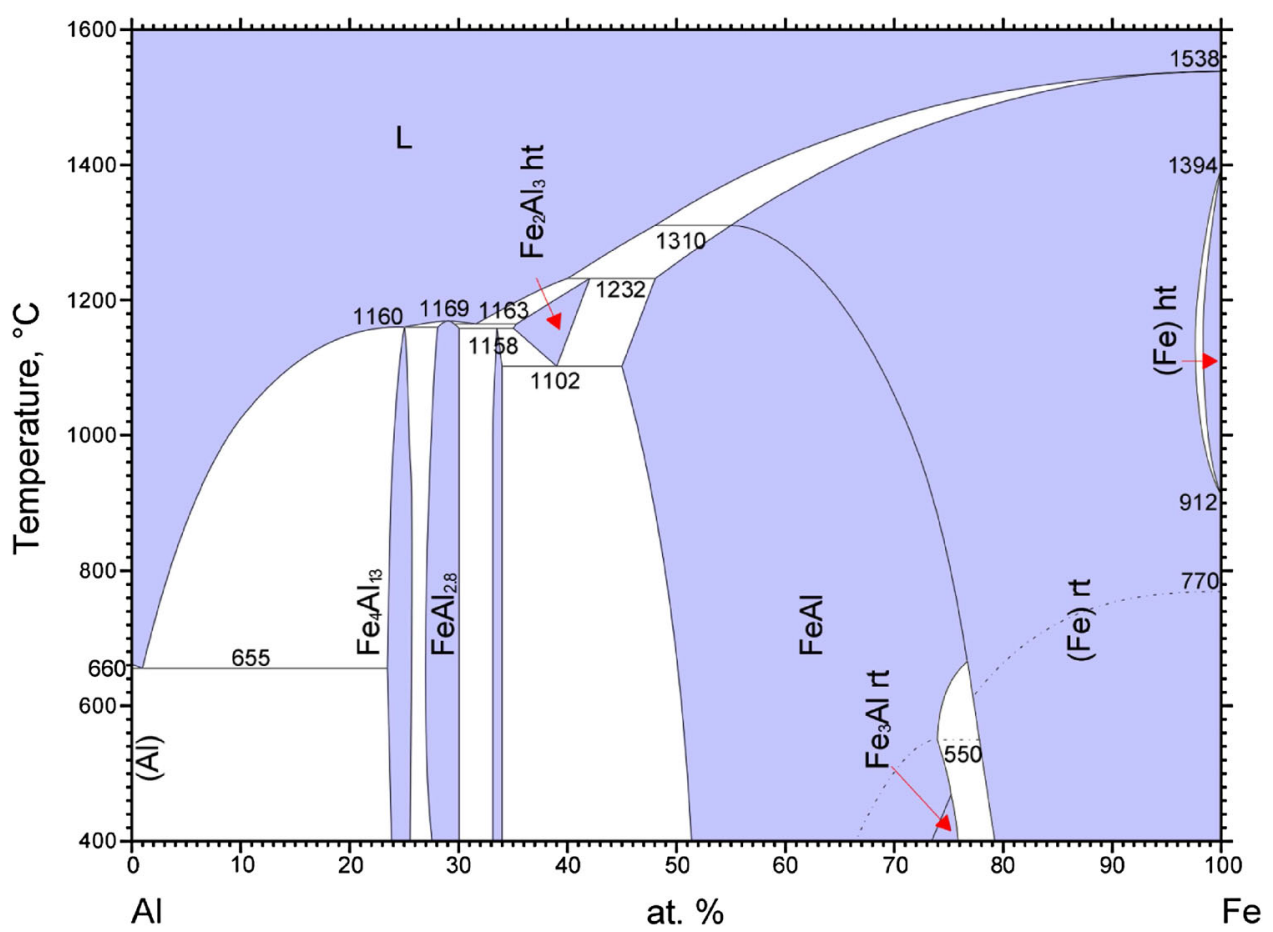

Fig. 1. Phase diagram for the Al-Fe binary system. ${ }^{11}$ Reprinted with permission of ASM International. All rights reserved.

Table I. Processes evaluated for joining of Fe to Al

\begin{tabular}{|c|c|c|}
\hline Solid state & Fusion & Mechanical fasteners \\
\hline $\begin{array}{l}\text { Explosive welding }(\mathrm{EXW})^{4,5} \\
\text { Magnetic pulse }{ }^{6,7} \\
\text { Friction weld }{ }^{24-27} \\
\text { Friction stir weld (FSW) })^{9,28-34} \\
\text { Friction stir spot welding }(\mathrm{FSSW})^{35-38} \\
\text { Friction bit joining (FBJ) }{ }^{43,44}\end{array}$ & $\begin{array}{l}\text { Resistance spot welding }(\mathrm{RSW})^{13-16} \\
\text { Electron beam welding }(\mathrm{EBW})^{17} \\
\text { Laser beam welding }(\mathrm{LBW})^{18-23}\end{array}$ & $\begin{array}{l}\text { Self-piercing rivets }(\mathrm{SPR})^{49-51} \\
\text { Clinching }{ }^{49,52}\end{array}$ \\
\hline
\end{tabular}

For bulk components with rotational symmetry, friction welding has been used commercially to produce $\mathrm{Fe}-\mathrm{Al}$ joints. In this process, one of the cylindrical pair is rotated at a high rate and pressed into the surface of the other cylinder. This creates friction at the interface, which either plasticizes or liquates the contacting surfaces and results in expulsion of the upset material that is forced out along with surface oxides. Typically, high-strength joints are formed by high friction and upsetting pressures, over a short time. ${ }^{25-28}$ Similar to LBW, the strength increases as the IMC, which contains various Al-rich intermetallics, decreases. ${ }^{25,26}$

Friction stir welds (FSWs) of Fe-Al have been demonstrated in both lap and butt welds. FSWs use a nonconsumable tool that plunges into the workpiece and stirs together the material that has been softened by friction and deformation heating as illustrated in Fig 3. In dissimilar butt FSW configurations, the $\mathrm{Al}$ is placed on the retreating side, as illustrated in Fig 4, often with the tool offset from the centerline into the
$\mathrm{Al}$ panel. This thrusts the plasticized $\mathrm{Al}$ into the faying surface of the Fe panel. ${ }^{29-35}$ The resulting stir zone, often referred to as an onion ring structure, is noted to contain petals of steel particles forming a composite-like structure in the fine-grained material. ${ }^{29-35}$ The formation of Al-rich intermetallics has also been observed, which have been attributed to the diffusion of Fe into $\mathrm{Al} .^{29,31}$ Similar to LBW, acceptable FSW properties can be obtained by maintaining a relatively small size of the intermetallic regions, as controlled by the process parameters. ${ }^{34}$

An adaptation of this process to local spots is called friction stir spot welding (FSSW). In some ways, FSSW is similar to FSW lap joints in that the material configuration along with careful control of the pin depth can control the IMC formation to produce good quality welds as illustrated in Fig $5{ }^{36-39}$ Additionally, by configuration of the lap joint with the $\mathrm{Al}$ on the top, the more favorable Al-rich intermetallic $\left(\mathrm{Fe}_{4} \mathrm{Al}_{13}\right.$ or $\left.\mathrm{FeAl}_{3}\right)$ is formed. ${ }^{38,40-43}$ 
The generic FSSW term encompasses a variety of processes that use a nonconsumable tool including pure spot FSW, refill FSW, and swing FSW. ${ }^{9}$ More recently a modified FSSW process known as friction bit joining (FBJ) has been demonstrated which uses a consumable

(a)

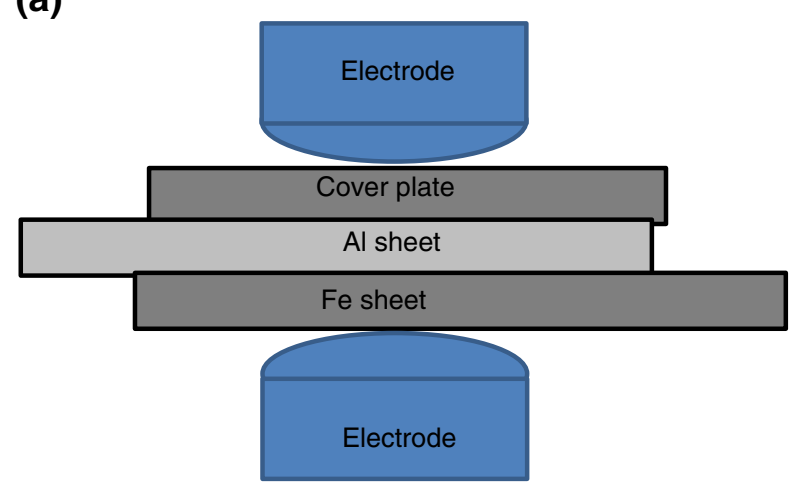

(b)

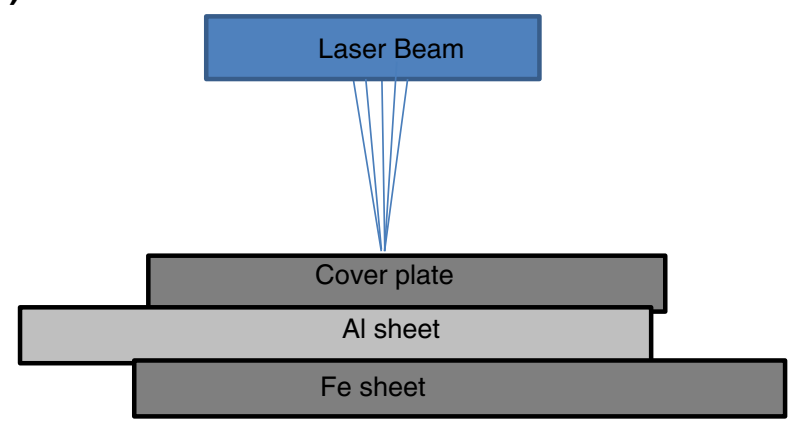

Fig. 2. Use of a cover plate to dissipate heat to Al sheet for RSW (a) and LBW (b) (Fig. 2a adapted from Ref. 15 and Fig. 2b adapted from Ref. 20). tool or joining bit. Rather than plunge a rotating tool into the workpiece, as with FSW and FSSW, the bit cuts through the top layers of the material and softens the surrounding sheet by friction, with the filler material provided by the consumable tool. ${ }^{44,45}$

\section{Automotive Industry}

The 65 million cars and 22 million commercial vehicles fabricated worldwide in 2013 makes this industry a major driver toward joining of very dissimilar materials. Current mandates toward improved fuel efficiency are causing automotive manufactures to reduce weight without sacrificing

\section{(a)}

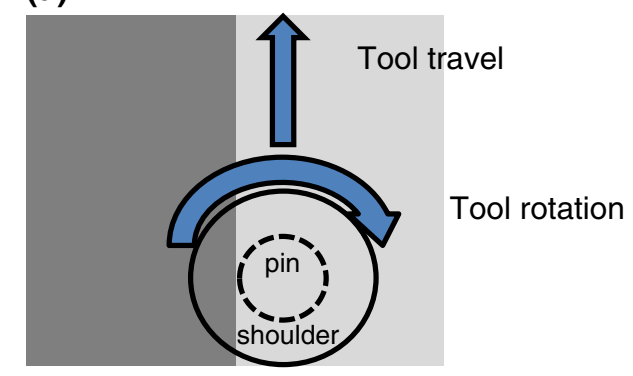

Fe plate Al plate

(b)

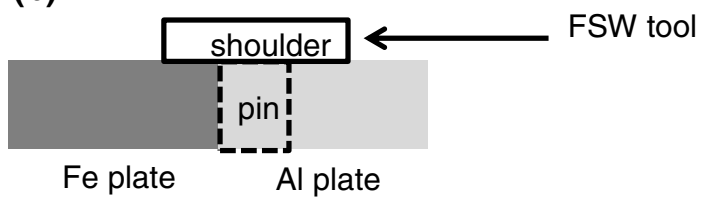

Fig. 4. Friction-stir welding configuration for a Fe to Al butt joint (figure adapted from Refs. 28-32, and 34).

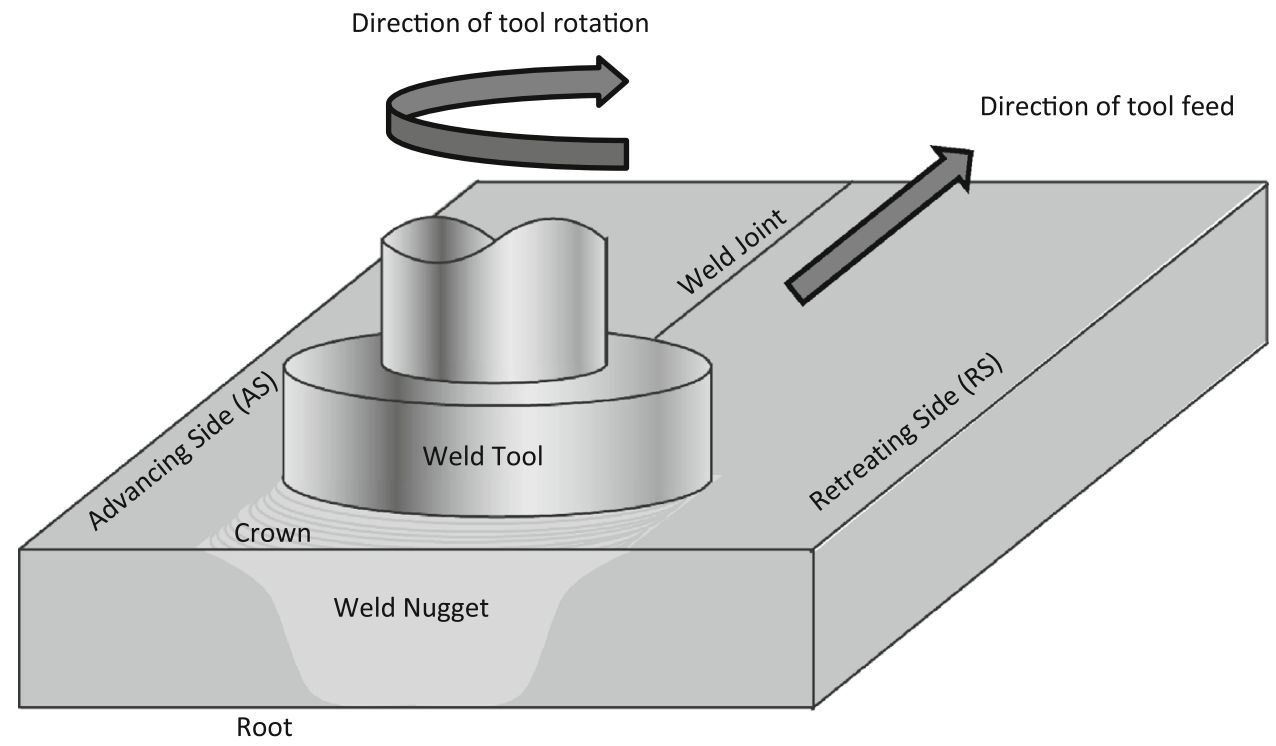

Fig. 3. Illustration of solid-state friction stir welding process. 


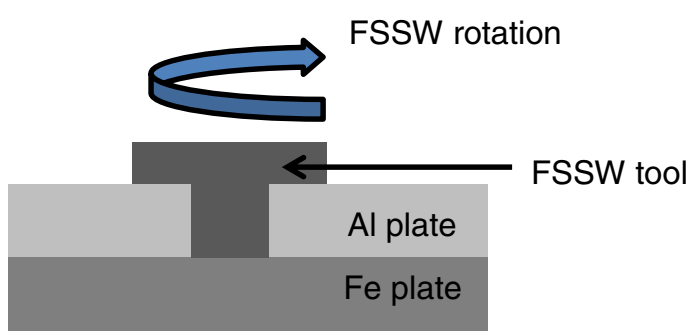

Fig. 5. FSSW configuration. Careful control of pin length promotes Al-rich intermetallic at interface with Fe plate. (Figure adapted from Refs. 35-38).

safety. ${ }^{46}$ Over the years, $\mathrm{Al}$ has been used to replace $\mathrm{Fe}$ in various finishing components such as engine blocks, wheels, bumpers, and hoods. ${ }^{47,48}$ More recently, the insertion of $\mathrm{Al}$ into the vehicle frame has been pursued as one alternative to decrease vehicle weight. The body in white (BIW) approach for steel vehicle frames used stamped body panels spot welded together, to which the other finishing components were bolted. Replacing these stamped body panels with $\mathrm{Al}$ for the space frame concept required some modification of the assembly line, including establishing RSW procedures for $\mathrm{Al}$ and its alloys. The material selection continues to be made on the basis of reducing weight while improving crash worthiness. While tradeoffs initially were made regarding the use of either all $\mathrm{Al}$ alloys or all $\mathrm{Fe}$ alloys, additional improvement can be made by developing processes to join steel and its alloys directly to $\mathrm{Al}$ and its alloys. A current evaluation of the BIW or space frame design based on overall part strength, corrosion, and cost will define the types of dissimilar material joints that will have to be developed on a production scale.

As advancements are made in methods to consolidate materials, their use often depends on ease of implementation. Most automotive designs rely heavily on RSW, often with up to 5000 to 8000 RSWs per vehicle. ${ }^{48}$ If the process parameters for these methods can be adjusted to produce a sound, robust joint, then the costs of implementation will be reduced. Thus, research continues on the development of RSW procedures for $\mathrm{Fe}$ to $\mathrm{Al}$ joints. ${ }^{12-15}$ The reduction of temperature by changing from RSW to solid state processes such as FSSW may provide an easier transition. ${ }^{9}$ To counter the tool wear in FSW/FSSW of steels, consumable tool bits have been proposed. ${ }^{44,45}$

In parallel with solid-state joining, mechanical fasteners such as either SPRs or clinch joints continue to be pursued in the automotive industry. ${ }^{50}$ Although mechanical fasteners are applied to the joining of $\mathrm{Al}$ alloys, research is ongoing to evaluate the techniques for $\mathrm{Al}$ to $\mathrm{Fe}$ joints. ${ }^{50-53}$ Both approaches use mechanical deformation in the production of a lap joint. While SPR uses a rivet to provide the interlocking, clinching directly provides the interlocking between the two sheets. Both are amenable to automation and are being considered to replace RSW. Surface oxidation is not an issue; therefore, no surface preparation is needed. However, because of the deformation that occurs, the resulting surface contains crevices that promote corrosion. This could be overcome by combining adhesive bonding with mechanical fasteners, but it adds another process thereby increasing production cost. $^{50}$

Although much research is still ongoing, automotive companies have already implemented solidstate welds of $\mathrm{Fe}-\mathrm{Al}$ in specialized models. The use of the FSW process was first implemented in the 2001 Volvo V70 rear seat frame. ${ }^{40}$ Since then the 2005 Ford GT and 2007 Audi R8 have used the FSW process in their space frames. ${ }^{40}$ Notably, the automotive companies seem to be cautious in placing the FSWs in easily accessible locations for repair. ${ }^{40}$ In contrast to this cautious nature, Honda has implemented a linear FSW process in their front subframe of the 2013 Accord to join $\mathrm{Fe}-\mathrm{Al}$ as illustrated in Fig $6 .^{40,54}$ Key to this implementation of this design was the fabrication of a robotic tool to control the FSW process in the assembly line. ${ }^{54}$ This replaced the previous bolted assembly used in the 2008 Accord. $^{54}$

To further the use of $\mathrm{Fe}-\mathrm{Al}$ joints, it is possible to produce the joint outside of the automotive factory. Starting in the early 1990s, tailor-welded blanks (TWBs) were incorporated into the U.S. automotive industry. ${ }^{55,56}$ Since then, TWBs have been mainstreamed into many production vehicles. The initial concept was to join different thicknesses of steel at the factory to produce a single part with different strengths or stiffnesses. ${ }^{55,56}$ Since then, the concept has been adapted to the use of aluminum and its alloys. ${ }^{57}$ Because this joining process can be done outside of the automotive assembly plant, it is easier for automotive fabricators to implement into production. A tailor-welded blank of $\mathrm{Fe}$ to $\mathrm{Al}$ could be brought into the factory floor and introduced into the BIW or space frame for joining to similar materials. This could enable the use of pressure techniques such as explosive bonding to form the intermetallic joint, which could then use the existing infrastructure for RSW of similar materials that are already developed and in place. However, as TWBs are usually stamped, formability of the joint area will have to be addressed. Because solid-state processes such as FSW result in a refined grain microstructure, it may have more application to subsequent forming than the solidification structure of fusion welding approaches. How other pressure bonding techniques will respond to subsequent deformation needs to be researched.

As automakers explore avenues to make cars lightweight and crashworthy, while reducing costs and meeting performance mandates, technology must continue to bring solutions forward for their consideration. Automotive making has evolved from initially labor intensive in the early twentieth century to fully automated in the twenty-first century. 


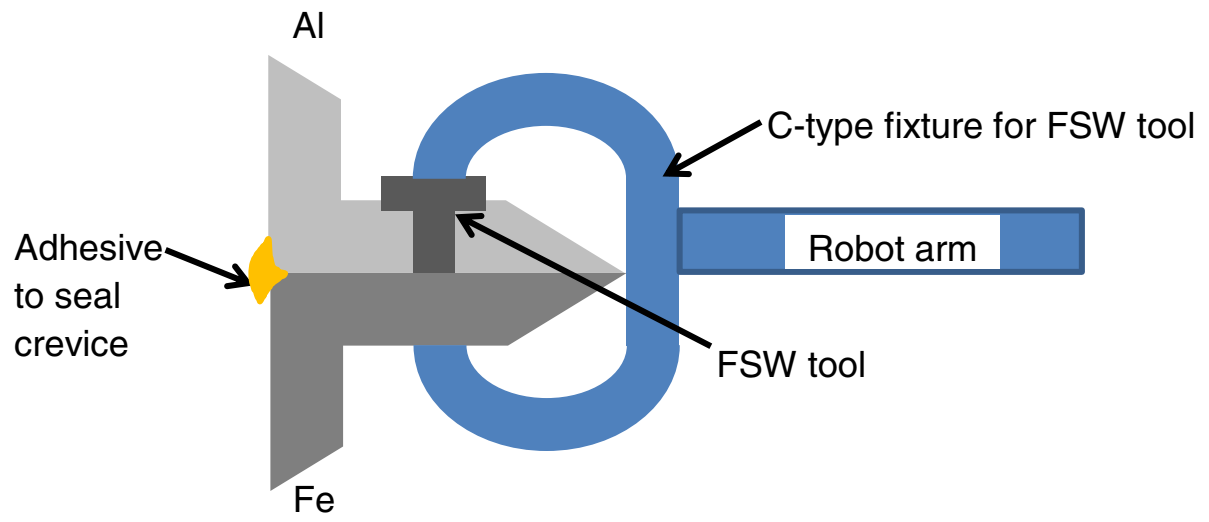

Fig. 6. Configuration of robotic friction-stir welding to join Al to Fe in the 2013 Honda Accord. (Figure adapted from Ref. 52).

Additional evolution is sure to occur in the next decades as driven by economic constraints not fully developed at this time.

\section{Corrosion}

There is very little currently in the literature regarding the corrosion issues within joining of very dissimilar metals such as $\mathrm{Al}$ or $\mathrm{Mg}$ to steel. Based on the electromotive force (emf) series, $\mathrm{Al}$ will act as an anode and $\mathrm{Fe}$ will act as the cathode, thereby corroding the $\mathrm{Al}$. Mechanical fasteners lend themselves more readily to the incorporation of a corrosion barrier, such as an adhesive, between the dissimilar metals. Careful design of metal placement or use of transition layers could be used to reduce the severity of the corrosion. The compositions of galvanized steels provide this transition between the $\mathrm{Fe}$ and $\mathrm{Al}$. The corrosion-resistance welding of dissimilar metals could also be addressed in design by incorporation of sacrificial anodes.

\section{SUMMARY}

Just as a piece-by-piece replacement of high strength-to-weight materials was not found to be optimum in the design of lightweight vehicles, a piece-by-piece insertion via welding or joining into existing fabrication lines is not optimum. Strides must be taken to advance the technology to ensure that engineering and fabrication have plenty of tools at their disposal.

\section{ELECTRONIC SUPPLEMENTARY MATERIAL}

The online version of this article (doi:10.1007/ s11837-014-1134-5) contains supplementary material, which is available to authorized users.

\section{REFERENCES}

1. G.E. Linnert, Welding Metallurgy: Carbon and Alloy Steels (Miami, FL: AWS, 1994), pp. 1-4.
2. J.V. Woodworth, Drop Forging, Die Sinking and Machine Forming of Steel (New York: Norman W. Henley, 1911), pp. 94-138.

3. S. Kou, Welding Metallurgy (Hoboken, NJ: Wiley, 2003), pp. $3-22$.

4. F. Findik, Mater. Des. 32, 1081 (2011).

5. Y.Zhang, S.S. Babu, C. Prothe, M. Blakely, J. Kwasegroch, M. LaHa, and G.S. Daehn, J. Mater. Process Technol. 211, 944 (2011).

6. V. Shribman and M. Blakely, Weld. J. 97, 56 (2008).

7. T. Aizawa, M. Kashani, and K. Okagawa, Weld. J. 86, 119s (2007).

8. J.L. Jellison, C.E. Albright, J. Devine, G. Harmon, GT.A. Kn orovsky, V.H. Winchell II, and J.C. Papritan, Welding Handbook, ed. R.L. O'Brien (Miami, FL: AWS, 1997), pp. 784-812.

9. R.S. Mishra and M.W. Mahoney, Friction Stir Welding and Processing (Materials Park, OH: ASM, 2007), pp. 1-49.

10. U.R. Kattner, B.P. Burton, Phase Diagrams of Binary Iron Alloys, ed. H. Okamoto (Materials Park, OH: ASM, 1993), pp. $12-48$.

11. U.R. Kattner, in ASM Alloy Phase Diagrams Center, eds. H. Okamoto, K. Cenzual (Materials Park, OH: ASM, 2006).

12. M.M. Atabaki et al., DTIC Online Report \#ADA586377 (2014).

13. J.E. Gould, Weld. J. 91, 23s (2012).

14. H. Oikawa, S. Ohmiya, T. Yoshimura, and T. Saitoh, Sci. Technol. Weld. Joi. 4, 80 (1999).

15. X. Sun, E.V. Stephens, M.A. Khaleel, H. Shao, and M. Kimchi, Weld. J. 83, 188x (2004).

16. R. Qiu, C. Iwamoto, and S. Sataonaka, Mater. Charact. 60, 156 (2009).

17. R. Qiu, C. Iwamoto, and S. Sataonaka, J. Mater. Process Technol. 209, 4186 (2009).

18. Z. Sun and R. Karppi, J. Mater. Process Technol. 59, 257 (1996).

19. K.J. Lee, S. Kumai, and T. Arai, Metall. Mater. Trans. 46, 1847 (2005).

20. K.J. Lee and S. Kumai, Metall. Mater. Trans. 47, 1178 (2006).

21. R. Borrisutthekul, T. Yachi, Y. Miyashita, and Y. Mutoh, Mater. Sci. Eng. 467A, 108 (2007).

22. G. Sierra, P. Peyre, F.D. Beaume, D. Stuart, and G. Fras, Mater. Charact. 59, 1705 (2008).

23. A. Mathieu, R. Shabadi, A. Deschamps, M. Suery, S. Mattei, D. Grevey, and E. Cicala, Opt. Laser Technol. 39, 652 (2007).

24. G. Liedl, R. Bielak, J. Ivanova, N. Enzinger, G. Figner, J. Bruckner, H. Pasic, M. Pudar, and S. Hampel, Phys. Proc. 12, 150 (2011).

25. M. Yilmax, M. Col, and M. Acet, Mater. Charact. 29, 421(2003).

26. E. Taban, J.E. Gould, and J.C. Lippold, Mater. Des. 31, 2305 (2010).

27. D. Ananthapadmanaban, V.S. Rao, N. Abraham, and K.P. Rao, Mater. Des. 30, 2642 (2009). 
28. S. Fukumoto, H. Tsubakino, K. Okita, M. Aritoshi, and T. Tomita, Scr. Mater. 42, 807 (2000).

29. C.M. Chen and R. Kovacevic, Int. J. Mach. Tool Manuf. 44, 1205 (2004).

30. H. Uzun, C. Dalle Donne, A. Argagnotto, T. Ghidini, and C. Gambaro, Mater. Des. 26, 41 (2005).

31. W-B. Lee, M. Schmuecker, U.A. Mercardo, G. Biallas, and S.-B. Jung, Scr. Mater. 55, 355 (2006).

32. T. Watanabe, H. Takayama, and A. Yanagisawa, J. Mater. Process Technol. 178, 342 (2006).

33. T. Tanaka, T. Morishige, and T. Hirata, Scr. Mater. 36, 756 (2009).

34. T. Chen, J. Mater. Sci. 44, 2573 (2009).

35. M. Dehghani, A. Amadeh, and S.A.A. Akbari, Mousavi. Mater. Des. 49, 433 (2013).

36. K. Yoshikawa, T. Harano, in Int. FSW Symp. Proc. (Cambridge, UK: TWI Int., 2001).

37. A. Elrefaey, M. Gouda, M. Takahashi, and K. Ikeuchi, J. Mater. Eng. Peform. 14, 10 (2005).

38. C-Y. Lee, D.J. Choi, Y.-M. Yeon, and S.-B. Jung, Sci. Technol. Weld. Join. 15(3), 216 (2009).

39. T. Liyanage, J. Kilbourne, A.P. Gerlich, and T.H. North, Sci. Technol. Weld. Join. 15, 500 (2009).

40. K.C. Colwell, Car \& Driver, May 2013, http://www.carand driver.com/features.

41. N. Yamamoto, et al., Mater. Sci. Forum 539-543, 3865 (2007).

42. M. Eliner and U. Burkhardt, Mater. Sci. Forum 150-151, 97 (1994).
43. W. Reisgen, C. Otten, and J. Schoenberger, Weld. World 58, 443 (2014).

44. M.P. Miles, K. Kohkonen, S. Packer, R. Steel, B. Siemssen, and Y.S. Sato, Sci. Technol. Weld. Join. 14, 72 (2009).

45. M.P. Miles, Z. Feng, K. Kohkonen, B. Weickum, R. Steel, and L. Lev, Sci. Technol. Weld. Join. 15, 325 (2010).

46. C.S.N. Shiau, J.S. Michalek, and C.T. Hendrickson, Trans. Res. Part A 43, 814 (2009).

47. G.S. Cole and A.M. Sherman, Mater. Charact. 35, 3 (1995).

48. M. Kleiner, M. Geiger, and A. Klaus, J. Manuf. Technol. 52, 521 (2003).

49. A. Kelkar, R. Roth, and J. Clark, J. Mater. 53, 28 (2001).

50. T. Barnes and I. Pashby, J. Mater. Process Technol. 99, 62 (2000).

51. X. He, I. Pearson, and K. Young, J. Mater. Process Technol. 199, 27 (2008).

52. Y. Abe, T. Kato, and K. Mori, J. Mater. Process Technol. 177 , 417 (2006).

53. C-J. Lee, J.-Y. Kim, S.-K. Lee, C.-C. Ko, and B.-M. Kim, J. Mater. Sci. Technol. 24, 123 (2010).

54. Y. Kusuda, Ind. Robot 40, 208 (2013).

55. I-Car Advantage, Technical Information for the Collision Industry, December 6, 2004, http://www.icar.com/html_pa ges/technical_information/advantage/advantage_online_ar chives/2004/120604.shtml.

56. F.I. Saunders and R.H. Wagoner, Metall. Mater. Trans. A 27A, 2605 (1996).

57. Y. Hovanski, J. Carsley, B. Carlson, S. Hartfield-Winsch, and S. Pilli, Int. J. Mater. Manuf. 7, 537 (2014). 